\title{
Synthesis of Anisotropic Mesostructured Gold Electrodeposits
}

\author{
M. Saitou \\ Department of Mechanical Systems Engineering, University of the Ryukyus, 1 Senbaru Nishihara-cho \\ Okinawa, 903-0213, Japan \\ E-mail: saitou@tec.u-ryukyu.ac.jp
}

doi: $10.20964 / 2016.08 .27$

Received: 5 May 2016 / Accepted: 8 May 2016 / Published: 7 July 2016

\begin{abstract}
Anisotropic mesostructured gold electrodeposits were synthesized on an indium tin oxide (ITO) glass from a solution of sodium disulfitoaurate (I) by a rectangular pulse current technique. Characterization of the gold electrodeposit was performed using a scanning electron microscope (SEM), X-ray diffraction (XRD), and energy dispersive X-ray spectrometry (EDX). Two shapes of the gold electrodeposits, which change with the solution temperature and the amplitude of the rectangular pulse current, are obtained; one is a star-like concave polygon with a lot of horn and the other is a truncated pyramid-like configuration. A gold thin film comprising of the star-like gold electrodeposit includes a large number of mesostructured pores. The pyramid-like electrodeposit has four triangular (111) planes. The gold electrodeposits are shown to be purely made of gold by the EDX measurement. The XRD measurement reveals a texture change in the gold thin film from the (111) plane to the (110) one with the growth time, whereas the surface morphology obeys the surface energy minimum.
\end{abstract}

Keywords: star-like gold electrodeposit, pyramid-like gold electrodeposit, texture coefficient, sodium disulfitoaurate (I), surface energy minimum

\section{FULLTEXT}

(C) 2016 The Authors. Published by ESG (www.electrochemsci.org). This article is an open access article distributed under the terms and conditions of the Creative Commons Attribution license (http://creativecommons.org/licenses/by/4.0/). 